\title{
University of Groningen
}

\section{P N.M.R. Nonequivalence of Diastereoisomeric 0,O-Dialkyl Phosphorodithioates}

\author{
Feringa, Bernard
}

Published in:

Journal of the Chemical Society, Chemical Communications

DOI:

10.1039/c39870000695

IMPORTANT NOTE: You are advised to consult the publisher's version (publisher's PDF) if you wish to cite from it. Please check the document version below.

\section{Document Version}

Publisher's PDF, also known as Version of record

\section{Publication date:}

1987

Link to publication in University of Groningen/UMCG research database

Citation for published version (APA):

Feringa, B. (1987). 31P N.M.R. Nonequivalence of Diastereoisomeric O,O-Dialkyl Phosphorodithioates. Journal of the Chemical Society, Chemical Communications, 27(9). https://doi.org/10.1039/c39870000695

\section{Copyright}

Other than for strictly personal use, it is not permitted to download or to forward/distribute the text or part of it without the consent of the author(s) and/or copyright holder(s), unless the work is under an open content license (like Creative Commons).

The publication may also be distributed here under the terms of Article 25fa of the Dutch Copyright Act, indicated by the "Taverne" license. More information can be found on the University of Groningen website: https://www.rug.nl/library/open-access/self-archiving-pure/taverneamendment.

Take-down policy

If you believe that this document breaches copyright please contact us providing details, and we will remove access to the work immediately and investigate your claim. 


\section{${ }^{31}$ P N.M.R. Nonequivalence of Diastereoisomeric O,O-Dialkyl Phosphorodithioates Ben L. Feringa \\ Department of Organic Chemistry, University of Groningen, Nijenborgh 16, 9747 AG Groningen, The Netherlands}

The enantiomeric excess of chiral alcohols can be obtained from the ratio of integrations of ${ }^{31} \mathrm{P}$ n.m.r. absorptions of diastereoisomeric $O, O$-dialkyl dithioates $(3, \mathrm{X}=\mathrm{S})$ derived therefrom; ${ }^{31} \mathrm{P}$ n.m.r. nonequivalence of L-cinchonidine salts of (3) was also observed.

Recently we reported new methods for determination of the enantiomeric excess (e.e.) of chiral alcohols, ${ }_{1,2}$ thiols, ${ }^{2,3}$ amino acid esters, and primary amines. ${ }^{4}$ The principle involved is the ${ }^{31} \mathrm{P}$ n.m.r. analysis of diastereoisomeric

$$
\left[\begin{array}{c}
R-0-P-0-R \\
\prod^{X} \\
P
\end{array}\right]
$$

(1)<smiles>CCC(C)OP(=O)(O)OC(C)CC</smiles>

$(R R . S S)^{*}$<smiles></smiles><smiles>[H][R9]=[W]</smiles><smiles>[R]O[PH]([X])([X])OCC</smiles>

(3)
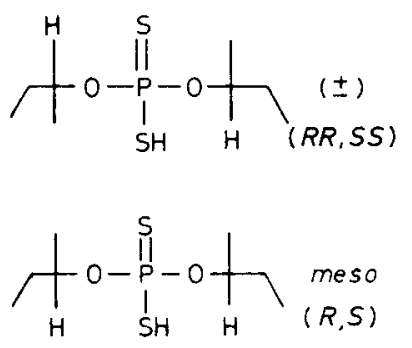

$(X=O, S \quad Y=H$, alkyl $R=$ alkyl)

\section{(4)}

Scheme 1.* indicates configuration at chiral centres, only one enantiomer of $(R R, S S)$-pair shown. phosphorus derivatives of these compounds using $\mathrm{PCl}_{3}$ (for alcohols) or $\mathrm{MePXCl}_{2}(\mathrm{X}=\mathrm{O}$ or $\mathrm{S})$ as derivatizing agents. Consequently no auxiliary chiral compound is necessary in order to determine the e.e. by this method. In the case of phosphonates (1), derived from racemic alcohols, a mixture of a $( \pm)$-pair and two meso-isomers is formed, as is illustrated for di-(s-butyl) phosphonate (2) (Scheme 1). When a non-pseudochiral phosphorus atom is present, as in (3), only a ( \pm )-pair and one meso-isomer are expected (Scheme 1). In general this stereochemical feature would be of advantage in e.e. determinations as only two ${ }^{31} \mathrm{P}$ n.m.r. signals will be present for racemic compounds. ${ }^{1,3}$ Phosphates $\left(3, X=O, R=\mathrm{Bu}^{\mathrm{s}}\right)$ show only one absorption at -0.16 p.p.m. $\left(\mathrm{CDCl}_{3}\right)$. It is remarkable that despite the high symmetry at phosphorus, ${ }^{31} \mathrm{P}$ n.m.r. non-equivalence for diastereoisomeric ( \pm and meso) $O, O$-di(s-butyl) hydrogen phosphorodithioate (4) (Figure 1) is observed. In accordance with expectation two singlets (50:50 ratio) for ( \pm )- and meso- $(4)(\Delta \delta 6.6 \mathrm{~Hz})$ and a single absorption for $(S, S)-(\mathbf{4})$ are found.

Various chiral alcohols were converted into phosphorodithioic derivatives by stirring at $20^{\circ} \mathrm{C}$ a $\mathrm{CDCl}_{3}$ solution of 2 equiv. of the alcohol and 1 equiv. of $O, O$-diphenyldithioic $\operatorname{acid}^{5}(\mathbf{5})$ as a thiophosphorylating agent (Scheme 2). Figure (d) shows the ${ }^{31} \mathrm{P}$ n.m.r. spectrum of (7) derived from racemic menthol (6) following this procedure. These results indicate that (5) can be used as an alternative reagent for determination of the e.e. of chiral alcohols, although chemical shift differences are generally smaller for the meso- and $( \pm)$-pair of these phosphorus derivatives. ${ }^{2,4}$ Furthermore we found that it is possible to discriminate between the meso- and $( \pm)$-phosphorodithioic acids using chiral tertiary amines. The (-)-cinchonidine salts of (4) and (7) clearly give ${ }^{31} \mathrm{P}$ n.m.r. nonequivalence only for one of the phosphorodithioic isomers (Figure 1). The low field ${ }^{31} \mathrm{P}$ n.m.r. absorption of acids (4) and (7) can therefore be assigned to the $(R R, S S)$-pair. These diastereoisomeric salts belong to dynamic diastereoisomeric systems ${ }^{6}$ and their n.m.r. nonequivalence critically depends 


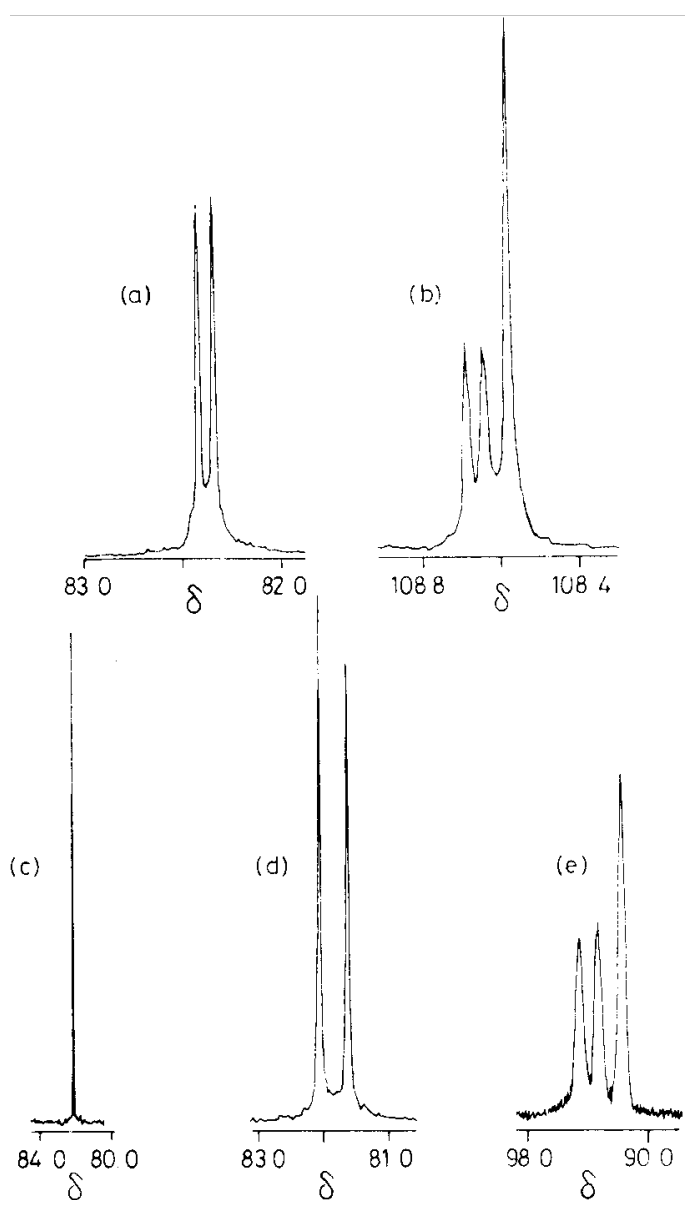

Figure 1. ${ }^{31} \mathrm{P}$ N.m.r. spectra at $80.988 \mathrm{MHz}\left[\mathrm{CDCl}_{3}\right.$, Nicolet NT-200, $85 \% \mathrm{H}_{3} \mathrm{PO}_{4}(\delta 0.0$ p.p.m.) as external standard]: (a) (4) derived from racemic s-butyl alcohol; (b) (-)-cinchonidine salt of racemic (4); (c) (7) derived from (-)-menthol; (d) (7) derived from racemic menthol; (e) (-)-cinchonidine salt of racemic (7).

on solvent, and amine structure and concentration. So far we have observed this phenomenon only using racemic phosphorodithioic acids with chiral tertiary amines in $\mathrm{CDCl}_{3}$.

As far as we know our results demonstrate for the first time ${ }^{31} \mathrm{P}$ n.m.r. nonequivalence of diastereoisomeric salts of

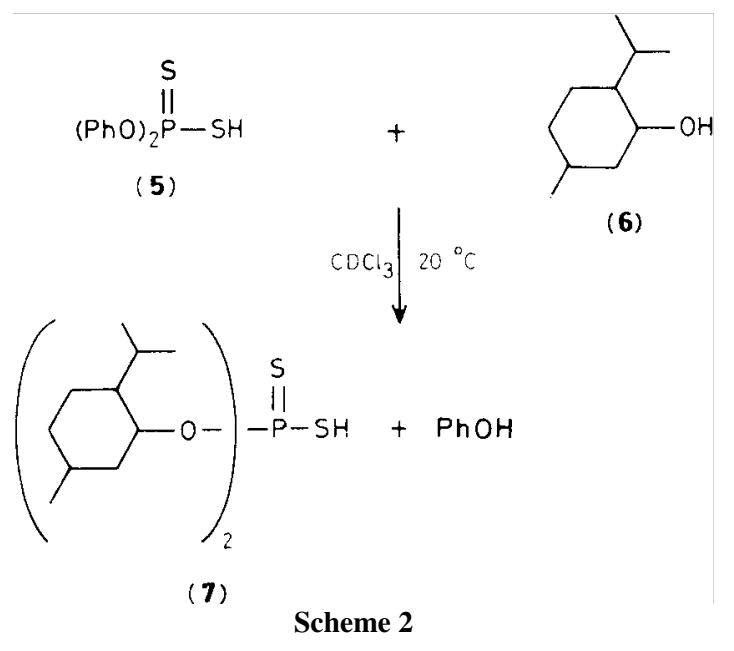

thiophosphates non-chiral at phosphorus. ${ }^{7,8}$ These observations might also be useful in elucidating the role of the prochiral phosphorus atom as a potential chiral binding site in phospholipids.?

Received, 19th December 1986; Com. 1800

\section{References}

1 B. L. Feringa, A. Smaardijk, and H. Wynberg, J. Am. Chem. Soc., 1985, 107, 4798.

2 B. L. Feringa, A. Smaardijk, H. Wynberg, B. Strijtveen, and R. M. Kellogg, Tetrahedron Lett., 1986, 27, 997.

3 B. Strijtveen, B. L. Feringa, and R. M. Kellogg, Tetrahedron, 1987, 43,123 .

4 B. L. Feringa, B. Strijtveen, and R. M. Kellogg, J. Org. Chem., 1986, 51, 5484.

5 J. Lefferts, K. C. Molloy, J. J. Zuckerman, I. Haiduc, C. Guta, and C. Ruse, Inorg. Chem., 1980, 19, 1662.

6 'Asymmetric Synthesis,' ed. J. D. Morrison, Academic Press, New York, vol. 1, 1982; A. Horeau and J. P. Guette, C.R. Acad. Sci., Ser. C., 1968, 276, 257.

7 M. Mikolajczyk, J. Omelánczuk, M. Leitloff, J. Drabowicz, A. Ejchart, and J. Jurczak, J. Am. Chem. Soc., 1978, 100, 7003.

8 The phosphorus atom in (3) does not constitute a chiral centre; for a recent discussion, see: K. Mislow and J. Siegel, J. Am. Chem. Soc., 1984, 106, 3319.

9 M. D. Tsai, R. T. Jiang, and K. Bruzik, J. Am. Chem. Soc., 1983, $105,2478$. 